\title{
Myocardial perfusion is impaired in asymptomatic patients post renal transplantation
}

Susie Parnham ${ }^{1,3^{*}}$, Suchi Grover ${ }^{3}$, Craig Bradbrook ${ }^{3}$, Govindarajan Srinivasan $^{3}$, Carmine DePasquale$^{1}$,

Richard Woodman ${ }^{4}$, Jonathan Gleadle ${ }^{2}$, Joseph Selvanayagam ${ }^{1,3}$

From 16th Annual SCMR Scientific Sessions

San Francisco, CA, USA. 31 January - 3 February 2013

\section{Background}

Cardiovascular disease is one of the commonest causes of mortality post-renal transplantation (RT), often in patients with no known cardiac disease. The cardiac phenotype in these patients is not clearly defined. Multi-parametric cardiovascular magnetic resonance (CMR) imaging enables concurrent assessment of myocardial function, perfusion and irreversible injury. We hypothesized that myocardial

perfusion reserve would be impaired in asymptomatic post-renal transplant patients when compared with hypertensive controls.

\section{Methods}

Twenty-two asymptomatic RT patients (3 months to 5 years post-transplant) with, no known history of ischemic heart disease) and 12 hypertensive controls underwent

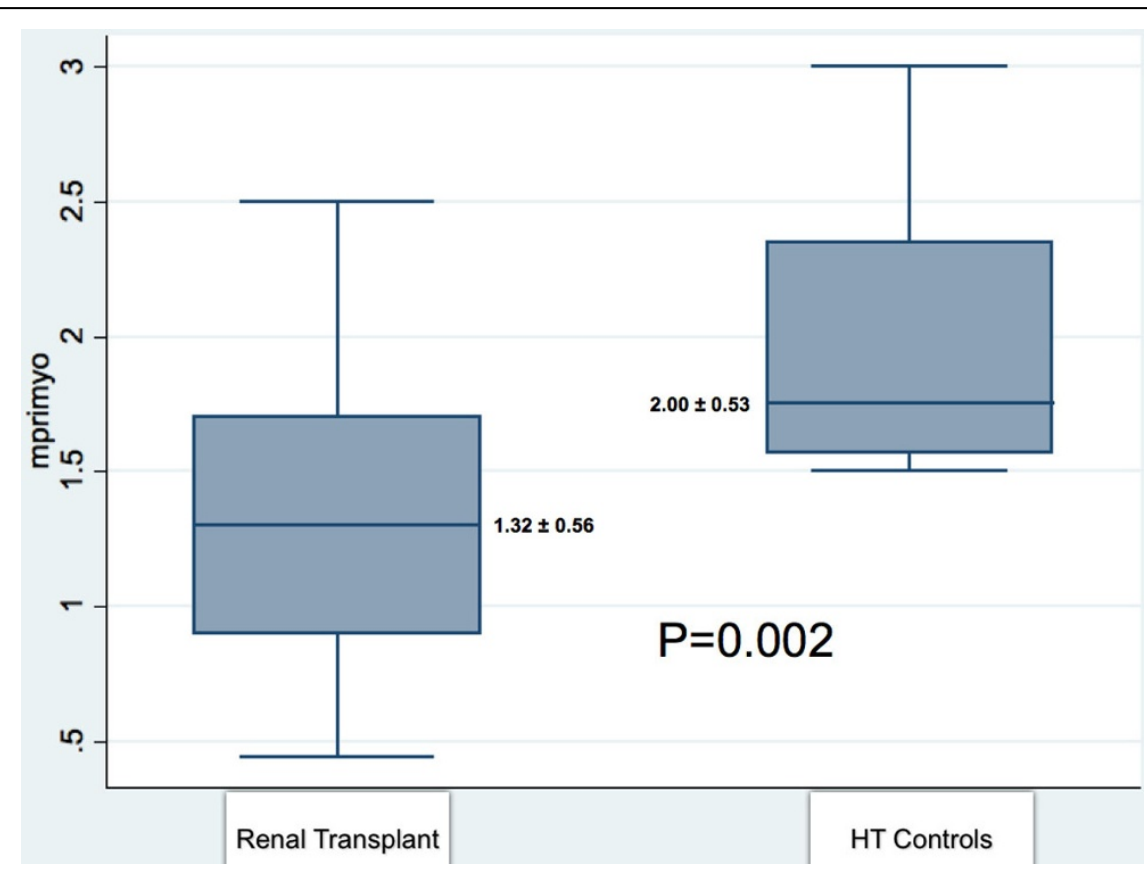

Figure 1 Global myocardial perfusion reserve index (mprimyo)

'Department of Cardiovascular Medicine, Flinders Medical Centre, Bedford

Park, SA, Australia

Full list of author information is available at the end of the article 
Table 1 Myocardial perfusion reserve index in Left Anterior Descending (LAD), Left Circumflex (LCx) and Right Coronary Artery (RCA) territories

\begin{tabular}{cccc}
\hline Coronary Artery Territories & Renal Transplant MPRI & Hypertensive Control MPRI & P Value \\
\hline LAD & $1.23 \pm 0.50$ & $1.93 \pm 0.46$ & 0.0005 \\
LCX & $1.17 \pm 0.53$ & $1.89 \pm 0.38$ & 0.0003 \\
RCA & $1.24 \pm 0.53$ & $1.79 \pm 0.31$ & 0.0029 \\
\hline
\end{tabular}

CMR scanning at $1.5 \mathrm{~T}$. Myocardial function, late enhancement, and first-pass perfusion at rest and stress was performed. Myocardial Perfusion Reserve Index (MPRI) was calculated as the ratio of hyperemic to resting myocardial blood flow by dividing the myocardial perfusion at stress by rest perfusion (corrected to rate pressure product). All analyses were performed using multivariate linear regression.

\section{Results}

Baseline clinical characteristics as well as left and right ventricular ejection fraction and volumes were similar for both RT and HT control groups. Mean interventricular septal thickness and LV mass were similar in both renal transplant and hypertensive control groups (LV septum: $1.1+/-0.3 \mathrm{~cm}$ RT vs $1.1+/-0.3 \mathrm{~cm} \mathrm{HT}$; LV mass index $127+/-35 \mathrm{~g} / \mathrm{m}^{2} \mathrm{RT}$ vs $127+/-33 \mathrm{~g} / \mathrm{m}^{2} \mathrm{HT}, \mathrm{p}>\mathrm{NS}$ ) . Rate Pressure Product (RPP) was similar in both groups. Global MPRI was significantly lower in the renal transplant group compared to the hypertensive control group (1.32 \pm 0.56 vs $2.00 \pm 0.53, \mathrm{P}=0.002$, Figure 1$)$. MPRI in all three coronary artery territories were lower in the RT group (see Table 1). One patient in RT group had late Gadolinium enhancement indicating sub-endocardial infarction.

\section{Conclusions}

Asymptomatic patients post renal transplantation have global reductions in myocardial perfusion compared to hypertensive controls, independent of the degree of LVH. This may reflect both severe coronary microvascular disease and/or undiagnosed epicardial coronary artery disease, and may in part explain the poorer cardiac outlook in these patients.

\section{Funding}

Flinders Medical Centre.

Flinders Research Centre.

\section{Author details}

'Department of Cardiovascular Medicine, Flinders Medical Centre, Bedford Park, SA, Australia. ${ }^{2}$ Renal Medicine, Flinders Medical Centre, Bedford Park, SA, Australia. ${ }^{3}$ Flinders Centre for Cardiovascular Magnetic Resonance Research, School of Medicine, Flinders University, Bedford Park, SA, Australia. ${ }^{4}$ Flinders Centre for Epidemiology and Biostatistics, School of Medicine, Flinders University, Bedford Park, SA, Australia.
doi:10.1186/1532-429X-15-S1-E68

Cite this article as: Parnham et al:: Myocardial perfusion is impaired in asymptomatic patients post renal transplantation. Journal of Cardiovascular Magnetic Resonance 2013 15(Suppl 1):E68.
Submit your next manuscript to BioMed Central and take full advantage of:

- Convenient online submission

- Thorough peer review

- No space constraints or color figure charges

- Immediate publication on acceptance

- Inclusion in PubMed, CAS, Scopus and Google Scholar

- Research which is freely available for redistribution

Submit your manuscript at www.biomedcentral.com/submit 